\title{
SCIENTIFIC REPORTS

\section{New Efficient Visible-Light-Driven Photocatalyst of Chitin-Modified Titanium Dioxide/Carbon Fiber Composites for Wastewater}

\begin{abstract}
Kui Mao, Xiaowen Wu*, Xin Min, Zhaohui Huang, Yan-gai Liu \& Minghao Fang
To improve the catalyst properties of $\mathrm{TiO}_{2}$ under visible light irradiation, chitin-modified $\mathrm{TiO}_{2}$ was synthesized via a hydrothermal method on the surface of carbon fibers. The microstructure and interface properties of the so-prepared photocatalyst were investigated via X-ray diffraction, scanning electron microscopy, $\mathrm{X}$-ray photoelectron spectroscopy, and UV-visible diffuse reflectance spectroscopy. Our results indicated that the synergetic effect of the crystal phase of $\mathrm{TiO}_{2}$, carbon fiber, and chitin is the main reason leading to the improvement of the photocatalytic activity of the composite catalyst. The modified $\mathrm{TiO}_{2}$ sample with chitin content of $0.6 \mathrm{wt} \%$ exhibited the highest photocatalytic activity under visible light irradiation when $\mathrm{RhB}$ was chosen as the target degradation product. Compared to the pure $\mathrm{TiO}_{2} /$ carbon fiber, the sample of $\mathrm{TiO}_{2} /$ carbon fiber with $0.6 \mathrm{wt} \%$ of chitin exhibits enhanced visible light activity with an apparent rate of degradation about 2.25 times. The enhancement of the photocatalytic performance of the sample with chitin can be attributed to the relatively high adsorption capacity of the particular network structure and photosensitivity of chitin, which can effectively separate the photoelectron-hole pair recombination. Furthermore, the new composite photocatalyst shows excellent catalytic stability after multiple degradation cycles, indicating that it is a promising photocatalytic material for degrading organic pollutants in wastewater.
\end{abstract}

With the economic development and population growth, the environmental pollution caused by organic matter is becoming more and more serious. The clean water that human beings depend on is gradually reducing. Thus, the environment cleaning or wastewater treatment has gained increasing attention ${ }^{1-3}$. Various technologies have been developed in the field of wastewater treatment, such as coprecipitation ${ }^{4}$, adsorption ${ }^{5}$, electrochemistry ${ }^{6}$, and membrane dialysis ${ }^{7}$. Unfortunately, although these methods have been applied to a varying extent, they still present several disadvantages. For instance, the coprecipitation method requires high $\operatorname{cost}^{8}$. The adsorption method does not completely treat the wastewater and cannot effectively convert the toxic substances into other non-toxic substances ${ }^{9}$. The electrochemical method leads to the formation of intermediate products with strong oxidative power towards the contaminant ${ }^{10}$. Finally, the membrane permeation is only suitable for small organic molecules and inorganic ions with poor selectivity. Although the operating conditions are straightforward, the efficiency is low with multiple factors affected (such as $\mathrm{pH}$, electrolyte, and electrode material) ${ }^{11}$. The photocatalytic technology has been widely researched in recent years, as it is one of the most environmentally friendly wastewater treatment methods because of its mild reaction conditions, low energy consumption, no formation of secondary pollutants, simple operation, and good selectivity ${ }^{12-15}$. Among many semiconductor materials, $\mathrm{TiO}_{2}$ is considered one of the most promising semiconductors photocatalytic for wastewater treatment and air purification due to its non-toxicity, high stability, low cost, and excellent photocatalytic activity ${ }^{16-18}$. However, owing to the high recombination rate of electron-hole pairs and the wide band gap, the ineffective response of $\mathrm{TiO}_{2}$ to visible light significantly limits its application ${ }^{19-21}$. Furthermore, although $\mathrm{TiO}_{2}$ has high photocatalytic activity, it still has a significant disadvantage that affects the large-scale industrial application of $\mathrm{TiO}_{2}{ }^{22} \cdot \mathrm{TiO}_{2}$ powders are difficult to separate and recover from water, causing secondary pollution ${ }^{23,24}$. To tackle the abovementioned issues, many researchers have focused on loading $\mathrm{TiO}_{2}$ powder onto a matrix material ${ }^{25,26}$. For example, Guo et al. directly

Beijing Key Laboratory of Materials Utilization of Nonmetallic Minerals and Solid Wastes, National Laboratory of Mineral Materials, School of Materials Science and Technology, China University of Geosciences (Beijing), 29 Xueyuan Road, Beijing, 100083, China. *email: xwwu@cugb.edu.cn 


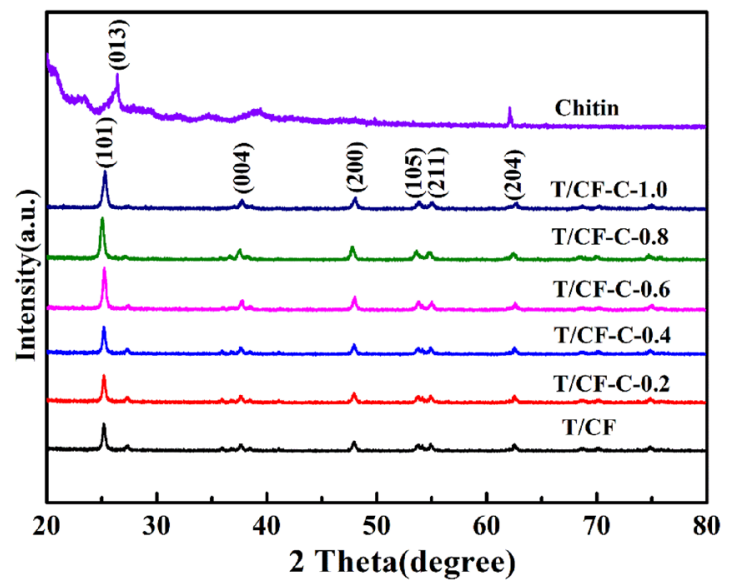

Figure 1. XRD patterns of chitin, T/CF, and the prepared composites.

\begin{tabular}{|l|l|l|l|l|l|l|}
\hline & T/CF & $\begin{array}{l}\text { T/CF-C- } \\
\text { Samples }\end{array}$ & $\begin{array}{l}\text { T/CF-C- } \\
\mathbf{0 . 4}\end{array}$ & $\begin{array}{l}\text { T/CF-C- } \\
\mathbf{0 . 6}\end{array}$ & $\begin{array}{l}\text { T/CF-C- } \\
\mathbf{0 . 8}\end{array}$ & $\begin{array}{l}\text { T/CF-C- } \\
\mathbf{1 . 0}\end{array}$ \\
\hline $\mathrm{S}_{\mathrm{BET}}\left(\mathrm{m}^{2} / \mathrm{g}\right)$ & 28.3204 & 31.0856 & 52.6843 & 73.3591 & 33.7821 & 26.1793 \\
\hline Pore Volume $\left(\mathrm{cm}^{3} / \mathrm{g}\right)$ & 0.1124 & 0.1746 & 0.2461 & 0.2652 & 0.1632 & 0.1298 \\
\hline
\end{tabular}

Table 1. Surface and pore volume characterization of T/CF and the prepared composites.

grew $\mathrm{TiO}_{2}$ nanosheets arrays on carbon fibers ${ }^{27}$. Long, M. et al. successfully used the sol-gel method to prepare cotton $/ \mathrm{TiO}_{2}$ composites with high photocatalytic activity and stability ${ }^{28}$. In addition, $\mathrm{TiO}_{2}$ nanoparticles have been incorporated into an organic matrix to form an organic-inorganic heterojunction photocatalytic composite $^{29}$. For example, Dassanayake, R. S. et al. successfully synthesized aerochitin-titania $\left(\mathrm{TiO}_{2}\right)$ composites, which showed high selectivity and multiple utilization performance ${ }^{30}$. Although carbon fiber and cotton have been demonstrated to be used as substrates for growing $\mathrm{TiO}_{2}$ nanoparticles, it is unfortunate that $\mathrm{TiO}_{2}$ nanoparticles are susceptible to agglomeration on substrates and have a poor synergistic effect, which limits their potential as catalyst supports. Although being an effective modifier due to its special network structure and excellent adsorption and being considered the second most abundant organic polymer on earth after cellulose, chitin has received little if not absent attention ${ }^{31-33}$. The structure of chitin is equivalent to that of cellulose polysaccharide with the hydroxyl functional group of C-2 substituted by the acetamido one, which has a high percentage of nitrogen (5-8\%) and outstanding adsorption properties ${ }^{34}$.

In this work, a method based on the coupling of $\mathrm{TiO}_{2}$ and chitin was reported for preparing chitin-modified $\mathrm{TiO}_{2} /$ Carbon fiber composites. Owing to the good bioadsorption, selectivity, and recyclability of chitin, this work aimed to improve the dispersion of $\mathrm{TiO}_{2}$ on the carbon fiber surface and to fully exert the synergistic effect of $\mathrm{TiO}_{2}$ with chitin and the carbon fiber. Indeed, the so-modified $\mathrm{TiO}_{2} /$ carbon fiber composites exhibit unique characteristics, such as recycling, recyclability, complete degradation and mineralization of organic matter. These modified $\mathrm{TiO}_{2}$ /Carbon fiber composites material can efficiently treat the organic matter in wastewater, thus providing a feasible solution for industrialized high-efficiency wastewater treatment.

\section{Results and Discussion}

The phases of chitin, T/CF, and the chitin-modified T/CF composites were characterized via XRD. As shown in Fig. 1, the prepared T/CF composites exhibit a representative diffraction peak of $\mathrm{TiO}_{2}$. There is no obvious diffraction peak of chitin: this may result from the hydrogen bond between $\mathrm{TiO}_{2}$ and chitin that interferes with the crystallization of chitin, indicating that $\mathrm{TiO}_{2}$ is completely embedded in the matrix of chitin as the inorganic phase. The characteristic peaks of $\mathrm{TiO}_{2}$ are at $25.2^{\circ}, 37.7^{\circ}, 48.1^{\circ}, 53.9^{\circ}, 55.1^{\circ}$, and $62.8^{\circ}$, corresponding to the (101), (004), (200), (105), (211), and (204) crystal faces of anatase $\mathrm{TiO}_{2}$ (JCPDS 21-1272) as they appear in the so-prepared photocatalyst ${ }^{35}$. Hence, the prepared photocatalytic material exhibits a high photocatalytic activity.

The pore structure of the prepared T/CF composites was further investigated by BET. The typical results BET data are shown in Table 1, where it can be seen that the addition of chitin significantly changed the specific surface area of the T/CF composites. The results show that T/CF-C- 0.6 sample has a specific surface area of $73.3591 \mathrm{~m}^{2} / \mathrm{g}$, which is 2.5 times higher than that of the unadded modifier of T/CF, resulting in enhanced adsorption of the dye on the composites. Since chitin itself is the particular network structure, $\mathrm{TiO}_{2}$ nanoparticles fill the chitin network voids to homo-disperse and increase the specific surface area of the sample. The $\mathrm{N}_{2}$ adsorption-desorption isotherm of samples of T/CF and T/CF-C-0.6 is shown in Fig. 2. It can be observed that the T/CF and T/CF-C-0.6 samples show a type IV adsorption isotherm with an $\mathrm{H}_{2}$ hysteresis loop in the range $\left(\mathrm{P} / \mathrm{P}_{0}\right)$ of $0.5-0.9$ according to the International Union of Pure and Applied Chemistry (IUPAC), indicating the presence of mesoporous $(2-50 \mathrm{~nm})^{36}$. This is beneficial to the multi-layer adsorption of pollutant molecules in aqueous solution. 


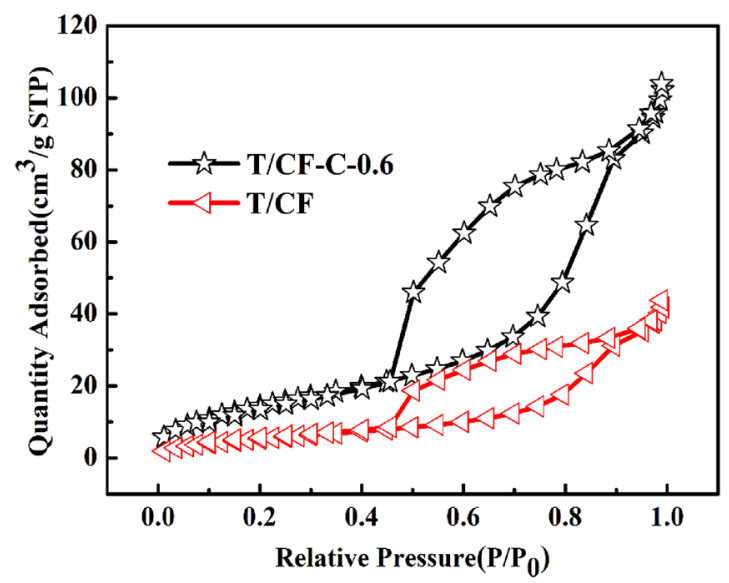

Figure 2. $\mathrm{N}_{2}$ adsorption and desorption isotherms of T/CF and T/CF-C-0.6.

Figure 3 shows the SEM images of the T/CF composites. As can be seen in Fig. 3a, the carbon fiber has a uniform diameter of $10 \mu \mathrm{m}$ with a smooth surface. Figure $3 \mathrm{~b}-\mathrm{g}$ shows the SEM images of composite samples of T/CF, T/CF-C-0.2, T/CF-C-0.4, T/CF-C-0.6, T/CF-C-0.8, and T/CF-C-1.0, respectively. It can be observed that $\mathrm{TiO}_{2}$ nanoparticles have been loaded on the surface of carbon fiber in different extents. Moreover, the SEM image of composites without chitin (Fig. 3b) shows that the $\mathrm{TiO}_{2}$ has poor loadability and dispersibility on the surface of carbon fiber. Chitin is a frequently used modifier to disperse the $\mathrm{TiO}_{2}$ nanoparticles on the carbon fiber surface more uniformly, reducing the aggregation. It can be shown in Fig. 3e,h,i,j that, when the amount of chitin added is $0.6 \%$, the loadability and dispersibility of $\mathrm{TiO}_{2}$ are relatively good, with the distribution of $\mathrm{TiO}_{2}$ nanoparticles being significantly more uniform than that of nanoparticles without chitin as a modifier. Due to the change of the zeta potential on the surface of $\mathrm{TiO}_{2}$ in the acidic solution, the presence of titanium acetate and the particular network structure of chitin can enhance the loading and dispersion of $\mathrm{TiO}_{2}$ nanoparticles on the carbon fiber surface, while providing a ratio of the specific surface area for adsorbing and degrading organic wastewater ${ }^{37,38}$. This is consistent with the results of XRD and BET.

To further clarify the surface chemical composition of the sample, we investigated the interfacial behavior between $\mathrm{TiO}_{2}$ and carbon fiber via XPS. Figure 4 shows the XPS spectrum of a T/CF-C- 0.6 sample. According to the $\mathrm{N} 1 \mathrm{~s}$ XPS spectrum in Fig. $4 \mathrm{a}$, the poor adhesion of anions to $\mathrm{TiO}_{2}$ is further revealed. A broadband at about $400 \mathrm{eV}$ can be fitted into two peaks at $398.8 \mathrm{eV}$ and $400.5 \mathrm{eV}$, which can be attributed to N-Ti-O and C-N, respectively ${ }^{39}$. The presence of $\mathrm{C}-\mathrm{N}$ indicates that chitin is attached to the carbon fiber surface. In Fig. $4 \mathrm{~b} \mathrm{O} 1 \mathrm{~s}$ XPS spectrum, there are three main peaks centered on $284.66 \mathrm{eV}, 285.16 \mathrm{eV}$, and $286.15 \mathrm{eV}$ that can be attributed to $\mathrm{sp}^{3}$ hybrid carbon $(\mathrm{C}-\mathrm{C})$ and $\mathrm{sp}^{2}$ hybrid carbon $(\mathrm{C}=\mathrm{C}) 1 \mathrm{~s}$ electrons, which form a $\mathrm{C}-\mathrm{OH}$ bond ${ }^{40}$. The sample has two peaks at $458.65 \mathrm{eV}$ and $464.45 \mathrm{eV}$ corresponding to the $\mathrm{Ti}^{4+}$ atoms in $\mathrm{TiO}_{2}$ (as shown in Fig. 4c). For the $\mathrm{O} 1 \mathrm{~s}$ electrons (Fig. 4d), the sample peak at $532.83 \mathrm{eV}$ corresponds to the surface of $\mathrm{TiO}_{2}$. Hydroxyl O has another strong peak at $529.6 \mathrm{eV}$, which is assigned to the oxygen bonded to $\mathrm{Ti}^{41}$.

Optical properties of T/CF samples were investigated via UV-Vis diffuse reflectance spectroscopy (DRS, Fig. 5a). Moreover, the band gaps of $\mathrm{TiO}_{2}$ and the prepared sample were calculated and listed in Fig. 5b. As shown in Fig. $5 \mathrm{a}$, by comparing he absorption starting points of the prepared T/CF composites and pure $\mathrm{TiO}_{2}$ at $420 \mathrm{~nm}$ in the visible light region under the same operating conditions, we can notice that the absorption extends and the optical absorption undergoes a red shift when chitin has been added. which may be related to the photosensitivity of chitin, isomerizing under photoirradiation and enhancing the visible light response. Therefore, we conclude that the coordination among $\mathrm{TiO}_{2}$, carbon fiber, and chitin molecules may be the main reason for the improvement of the photocatalytic activity of the catalyst.

The photocatalytic activity of the T/CF composites was investigated by measuring the photodegradation of $\mathrm{RhB}$ in aqueous solution $(50 \mathrm{mg} / \mathrm{L})$ under visible light irradiation (Fig. 6a). For comparison, the photocatalytic activities of pure chitin, carbon fiber, and $\mathrm{TiO}_{2}$ were also determined under the same operating conditions. It can be seen from Fig. $6 \mathrm{a}$ that the concentration of the control RhB solution remains unchanged upon direct irradiation, while the strength of the RhB solution with chitin is reduced by about $20 \%$ at a reaction time of 180 minutes, which can be attributed to the strong adsorption of $\mathrm{RhB}$ on porous chitin materials ${ }^{42}$. The T/CF-C-0.6 sample exhibits the highest adsorption capacity and the degradation rate for $\mathrm{RhB}$, which is almost 4 times higher than that of pure $\mathrm{TiO}_{2}$. However, due to the shielding effect, an excessive amount of adsorption dye will reduce its activity. The higher performance of the composites can be attributed to the synergistic effect of the $\mathrm{TiO}_{2}$ and chitin crystal phases, the high surface area, and the porous structure of the composites. $\mathrm{The}^{\mathrm{TiO}} \mathrm{O}_{2}$ nanoparticles exhibit excellent photocatalytic efficiency by transferring photoelectrons from the bulk to the surface and reducing the recombination rate of hole-electron pairs. The kinetic data of RhB photodegradation were obtained by the first-order reaction model as follows [Eq. (1)], 

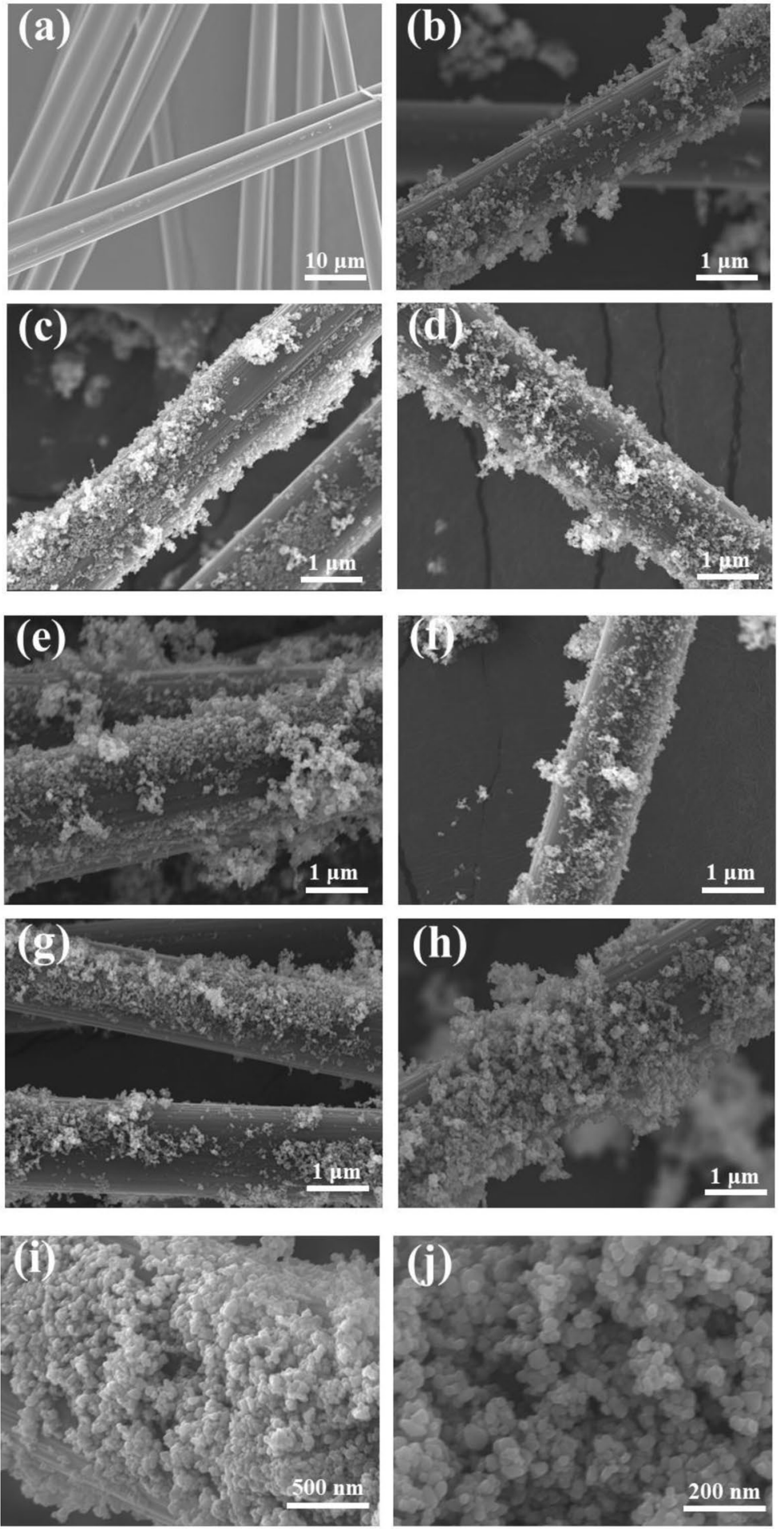

Figure 3. SEM images of carbon fiber (a), T/CF, T/CF-C-0.2, T/CF-C-0.4, T/CF-C-0.6, T/CF-C-0.8, and T/CFC-1.0, respectively $(\mathbf{b}-\mathbf{g})$, and T/CF-C-0.6 $(\mathbf{h}-\mathbf{j})$.

$$
\ln \left(\frac{C}{C_{0}}\right)=-K_{o b s} t
$$

Where $k_{o b s}$ is the apparent first-order rate constant $\left(\mathrm{min}^{-1}\right), C_{0}$ is the initial $\mathrm{RhB}$ concentration $(\mathrm{mol} / \mathrm{L})$, and $C$ is the $\mathrm{RhB}$ concentration $(\mathrm{mol} / \mathrm{L})$ in the aqueous solution at time t. The kinetic curve of degradation of $\mathrm{RhB}$ as a function of the T/CF composites is displayed in Fig. 6b. All photocatalysts are suitable for pseudo first-order models. Our kinetic results show that the $k_{o b s}$ values of chitin, T/CF,T/CF-C-0.2, T/CF-C-0.4, T/CF-C-0.6, T/CF-C-0.8, 

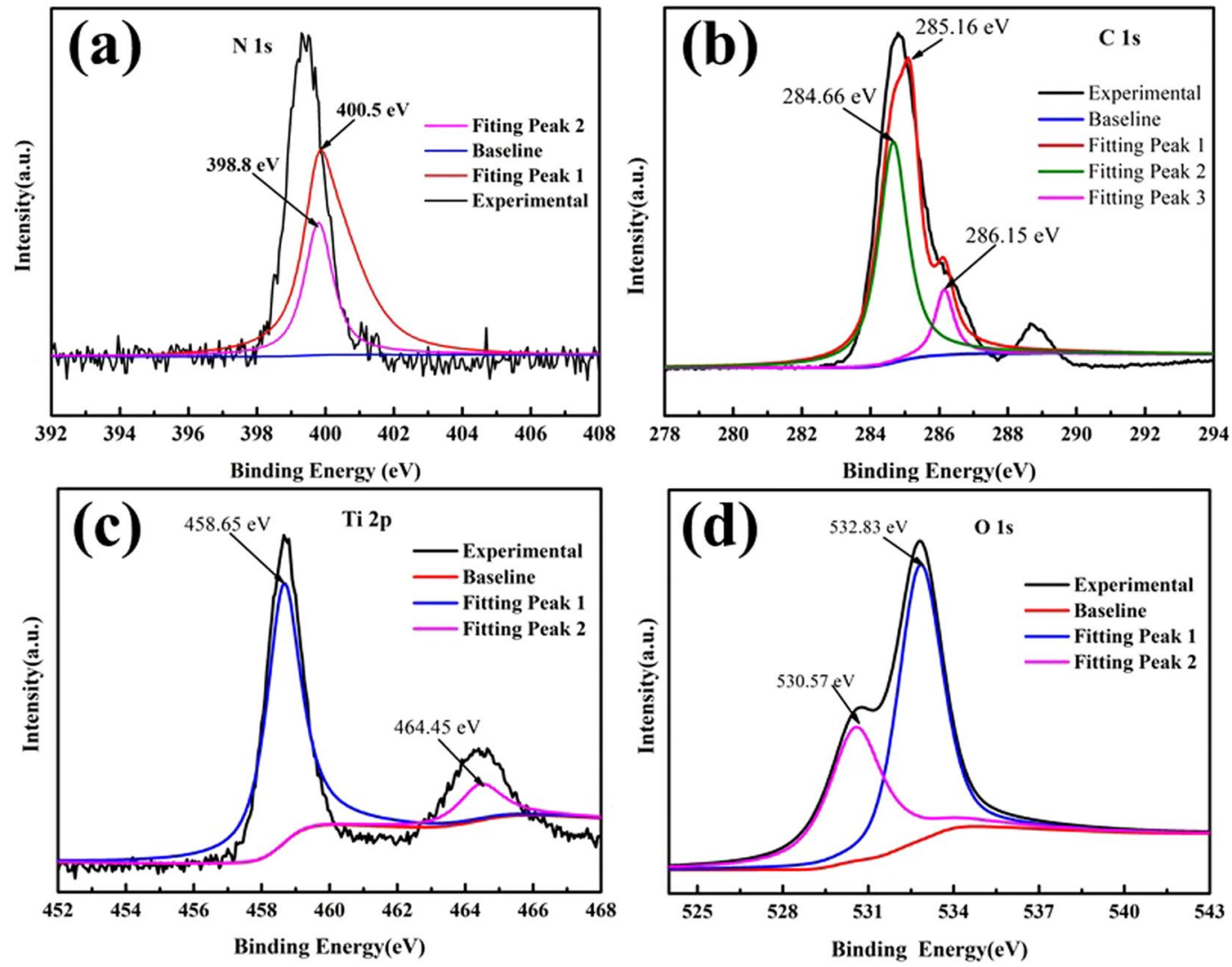

Figure 4. XPS spectra of T/CF-C-0.6 sample N 1 s (a), C 1 s (b), Ti $2 p$ (c), and O 1 s (d) electrons in the composites.
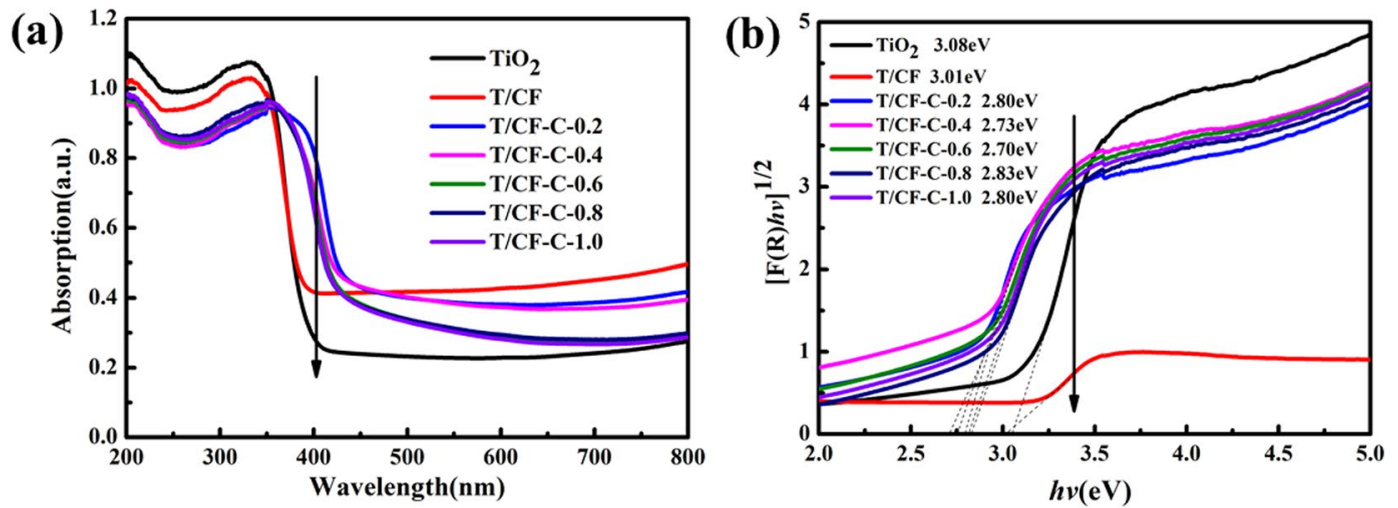

Figure 5. The UV-Vis DRS spectra (a) and band gaps of chitin, T/CF, and so-prepared composites (b).

T/CF-C-1.0, and carbon fiber are $0.0035 \mathrm{~min}^{-1}, 0.01021 \mathrm{~min}^{-1}, 0.01565 \mathrm{~min}^{-1}, 0.01888 \mathrm{~min}^{-1}, 0.02539 \mathrm{~min}^{-1}$, $0.01459 \mathrm{~min}^{-1}, 0.01209 \mathrm{~min}^{-1},>10^{-4} \mathrm{~min}^{-1}$, respectively. Therefore, the T/CF-C- 0.6 sample obtained the best photocatalytic efficiency, which is 2.5 times higher than that of T/CF. Indeed, it is known that a photocatalyst having a relatively high specific surface area is advantageous for increasing catalytic activity. The T/CF-C-0.6 sample has the highest specific surface area and the highest catalytic activity, indicating that small grain size and small band gap width should be the key factors for improving the photocatalytic activity. This is consistent with our previous BET results shown in Table 1. In this case, the excellent photocatalytic activity can be attributed to the direct adsorption of $\mathrm{RhB}$ on $\mathrm{TiO}_{2}$ and chitin as well as the photodegradation of the adsorbed dye on the $\mathrm{TiO}_{2}$ catalytic surface under visible light irradiation. The photocatalytic degradation can be enhanced by increasing the amount of dye adsorbed on the adsorbent; therefore, the action of chitin is indispensable in photocatalytic degradation because of its porous structure and high surface area, providing a more easily available adsorption site. The stability of $\mathrm{TiO}_{2}$ and chitin loaded on carbon fiber was evaluated by performing a cyclic experiment of $\mathrm{RhB}$ photocatalytic degradation. After each test, the used $\mathrm{TiO}_{2} /$ carbon fiber composites were dried at $80^{\circ} \mathrm{C}$ after 

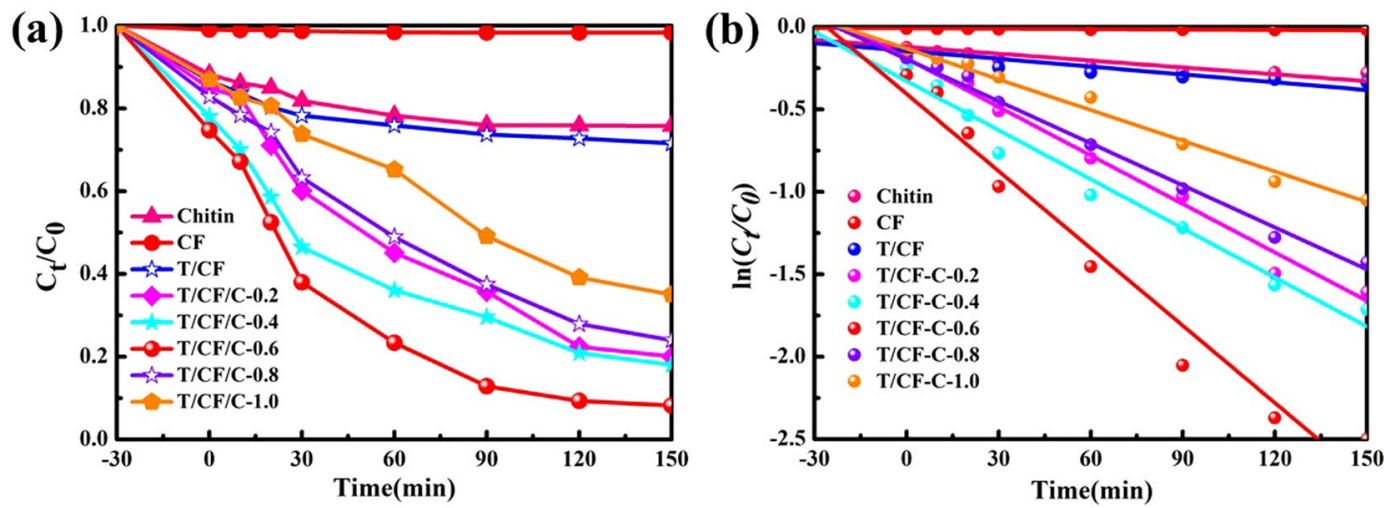

Figure 6. Photocatalytic degradation of $\mathrm{RhB}$ with $\mathrm{T} / \mathrm{CF}$ composites as photocatalysts under visible light (a) and linear transform of the kinetic curves of the RhB degradation (b).

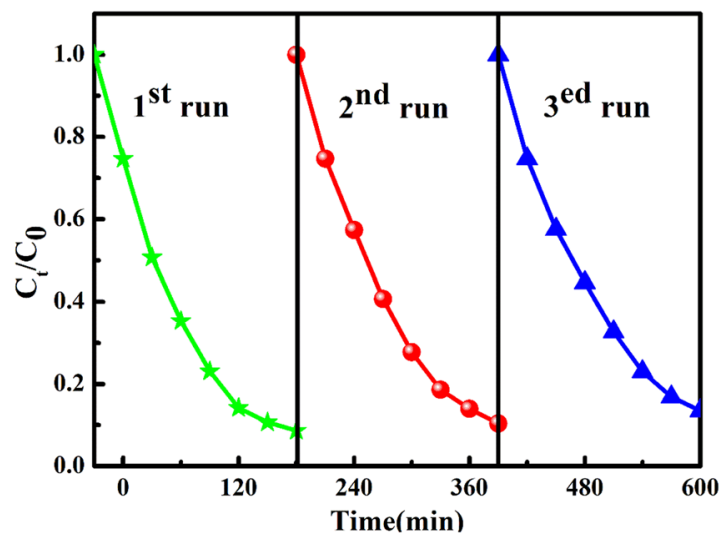

Figure 7. Reusability test of the T/CF-C-0.6 sample under visible light.

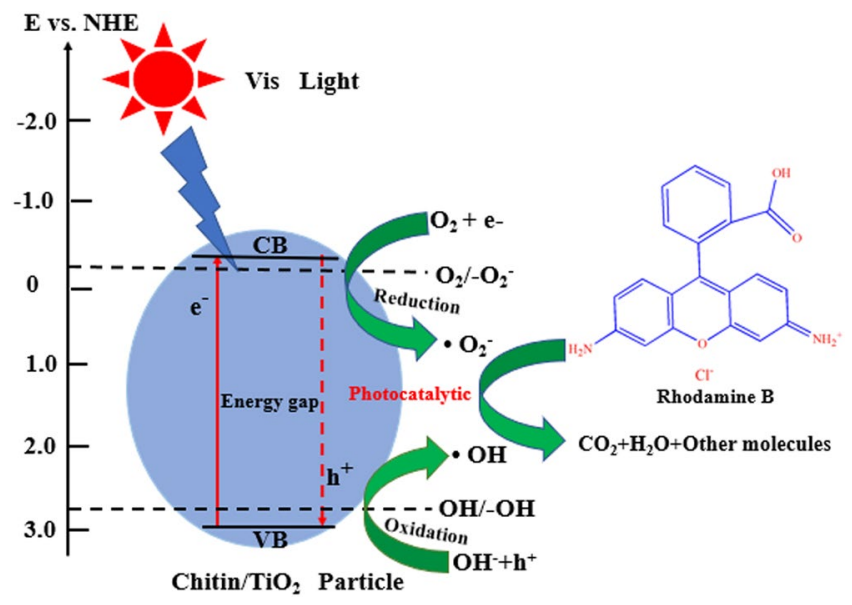

Figure 8. Proposed mechanisms for the $\mathrm{RhB}$ degradation of the so-prepared composite photocatalysts under visible light.

being washed by deionized water. The reusability results of the T/CF-C-0.6 sample are reported in Fig. 7. Indeed, the $\mathrm{RhB}$ degradation rate of T/CF composites has not decreased significantly after three reaction cycles, which implies that the so-synthesized T/CF photocatalyst exhibits good reusability. These results indicate that the nanoparticles are stable on the carbon fiber surface, while a strong interaction exists between these two materials, which will not peel off as the reaction progresses. Furthermore, the photocatalytic degradation functions of the modified T/CF composites are reproducible. Figure 8 illustrates the process of RhB degradation caused by T/CF composites. Upon irradiation, electrons are directly transferred from the valence band into the conduction band 
of $\mathrm{TiO}_{2}$, while the molecular oxygen $\left(\mathrm{O}_{2}\right)$ is reduced to superoxide radicals $\left(\mathrm{O}^{-2}\right)$. The hole electrons then react with water to form hydroxyl radicals $(\mathrm{OH})^{43}$. Subsequently, under visible light irradiation, these free radicals are responsible for the degradation of the adsorbed $\mathrm{RhB}$ molecules into inorganic ions and small molecules, such as water and carbon dioxide.

\section{Conclusions}

In summary, chitin-modified $\mathrm{TiO}_{2}$ nanoparticles with excellent photocatalytic properties in the region of visible light were synthesized successfully on the surface of carbon fiber using the hydrothermal method. Acting as a modifier and adsorbent, the addition of chitin not only broadened the photoresponse range but also improved the photocatalytic performance of $\mathrm{TiO}_{2}$. Indeed, photocatalytic analysis results showed that modified $\mathrm{T} / \mathrm{CF}$ composites have better adsorption and photocatalytic properties than single chitin and $\mathrm{TiO}_{2}$ nanoparticles under visible light. The apparent rate constant of degradation of the T/CF-C-0.6 sample was approximately 2.25 times higher than that of T/CF. In addition, T/CF-C-0.6 sample showed good stabilization of catalysis after three cycles of the test. The present work provides an effective route to enhance the catalysis performance of $\mathrm{TiO}_{2}$ in the visible light region and extend their application to various fields, such as solar energy conversion and self-cleaning, especially photocatalytic degradation of organic pollutant in wastewater.

\section{Methods}

Tetrabutyl titanate (TBT) purchased from Sinopharm Chemical Reagent Ltd. (China) was chosen as the precursor of $\mathrm{TiO}_{2}$. Glacial acetic acid $\left(\mathrm{CH}_{3} \mathrm{COOH}, 99.8 \%\right)$ and ethanol $\left(\mathrm{C}_{2} \mathrm{H}_{5} \mathrm{OH}, 99.7 \%\right)$ purchased from Beijing Chemical Reagent Ltd. (China) were used as the catalyst and solvent, respectively. Chitin was purchased from Yuhuan Ocean Biochemistry Co. Ltd. (China). Carbon fiber (CF) was purchased from Nantong Senyou carbon fiber Co. $\mathrm{Ltd}$. All reagents were of analytical grade and used without further purification. $\mathrm{TiO}_{2} /$ carbon fiber composites were prepared via hydrothermal method. During the classical synthesis process, $2.5 \mathrm{~mL}$ of TBT was slowly added dropwise to $15 \mathrm{~mL}$ of absolute ethanol, to which $5 \mathrm{~mL}$ of glacial acetic acid is added and then stirred for 3 hours. $0.2 \mathrm{wt} \%, 0.4 \mathrm{wt} \%, 0.6 \mathrm{wt} \%, 0.8 \mathrm{wt} \%$, and $1.0 \mathrm{wt} \%$ of chitin were thereafter added to the mixed solution as a modifier. After further stirring for another hour, the solution was then transferred to a Teflon stainless-steel autoclave with a total volume of $25 \mathrm{ml}$. With this done, acetone-treated carbon fiber was immersed in the solution. The hydrothermal synthesis was carried out by placing the solution in an oven set at $180^{\circ} \mathrm{C}$ for 24 hours. When the autoclave has cooled to room temperature, the carbon fiber was taken out and ultrasonically washed in an aqueous ethanol solution for 2 minutes. It was then dried in an oven set at $150{ }^{\circ} \mathrm{C}$ for 8 hours. Finally, the photocatalytic material of pure $\mathrm{TiO}_{2} /$ carbon fiber as well chitin-modified $\mathrm{TiO}_{2} /$ carbon fiber composites are obtained, labeled as T/CF, T/CF-C-0.2, T/CF-C-0.4, T/CF-C-0.6, T/CF-C-0.8, T/CF-C-1.0, depending on different amount of modifier of chitin: $0.2 \mathrm{wt} \%, 0.4 \mathrm{wt} \%, 0.6 \mathrm{wt} \%, 0.8 \mathrm{wt} \%$, and $1.0 \mathrm{wt} \%$, respectively.

The crystal phases were characterized via a powder X-ray diffraction (XRD, TD-3500X, Dandong Tongda Technology Co., Ltd.), operating at $40 \mathrm{kV}$ and $40 \mathrm{~mA}$ with a $\mathrm{Cu} \mathrm{K \alpha}$ irradiation. The surface morphologies were observed via scanning electron microscopy (SEM, Carl Zeiss, SIGMA 500, Germany). The UV-vis diffuse reflectance spectra were recorded by UV2550 UV/vis spectrophotometer (Shimadzu Corporation Japan) with the scanning range set at $200-800 \mathrm{~nm}$, using $\mathrm{BaSO}_{4}$ as the reference. X-ray photoelectron spectra (XPS) were recorded with a Kratos AXIS Ultra DLD XPS instrument equipped with an Al Ko source at $10^{-9}$ Torr. The specific surface and pore size distribution of the sample were measured by the US Mike TRISTAR II $3020 \mathrm{M}$ for nitrogen adsorption/desorption. The photocatalytic activity of these prepared T/CF composites was measured by the time evolution of photodegradation of rhodamine $\mathrm{B}(\mathrm{RhB})$ under a $500 \mathrm{~W}$ Xenon lamp with a $420 \mathrm{~nm}$ cut-off filter. During the process of testing photocatalytic performance, the amount of photocatalyst should be consistent. In a typical procedure, $50 \mathrm{mg}$ of the $\mathrm{TiO}_{2} /$ carbon fiber composites were added into an aqueous solution of $\mathrm{RhB}(50 \mathrm{~mL}, 50 \mathrm{mg} / \mathrm{L})$. Then, the mixture stirred in the dark for $30 \mathrm{~min}$ at room temperature to achieve the adsorption-desorption equilibrium. At the defined time intervals, $3 \mathrm{~mL}$ of the solution was taken from the reactor. The concentration of $\mathrm{RhB}$ in the suspension was monitored using the UV-vis spectrophotometer at the intensity of the absorption peak of $554 \mathrm{~nm}$; the photocatalytic activities of the samples were calculated from the decrease amount of RhB.

Received: 21 May 2019; Accepted: 24 October 2019;

Published online: 08 November 2019

\section{References}

1. Xiao, S., Wang, Z., Ma, H., Yang, H. \& Xu, W. Effective removal of dyes from aqueous solution using ultrafine silk fibroin powder. Adv. Powder. Technol. 25, 574-581 (2014).

2. Zhang, Y. J., Liu, L. C., Xu, Y., Wang, Y. C. \& Xu, D. L. A new alkali-activated steel slag-based cementitious material for photocatalytic degradation of organic pollutant from waste water. J. Hazard. Mater. 209, 146-150 (2012).

3. Gągol, M., Przyjazny, A. \& Boczkaj, G. Wastewater treatment by means of advanced oxidation processes based on cavitation - A review. Chem. Eng. J. 338, 599-627 (2018).

4. Wu, L., Cao, J., Wu, Z., Zhang, J. \& Yang, Z. The mechanism of radioactive strontium removal from simulated radioactive wastewater via a coprecipitation microfiltration process. J. Radioanal. Nucl. Chem. 314, 1973-1981 (2017).

5. Lee, C. G., Lee, S. \& Park, J. A. Removal of copper, nickel and chromium mixtures from metal plating wastewater by adsorption with modified carbon foam. Chemosphere. 166, 203-211 (2017).

6. Tran, T.-K., Chiu, K.-F., Lin, C.-Y. \& Leu, H.-J. Electrochemical treatment of wastewater: Selectivity of the heavy metals removal process. Int. J. Hydrog. Energy. 42, 27741-27748 (2017).

7. Han, D., Yu, X., Chai, Q., Ayres, N. \& Steckl, A. J. Stimuli-Responsive Self-Immolative Polymer Nanofiber Membranes Formed by Coaxial Electrospinning. ACS Appl. Mater. Interfaces. 9, 11858-11865 (2017).

8. Zhang, T., Gregory, K., Hammack, R. W. \& Vidic, R. D. Co-precipitation of radium with barium and strontium sulfate and its impact on the fate of radium during treatment of produced water from unconventional gas extraction. Environ. Sci. Technol. 48, 4596-4603 (2014). 
9. Mailler, R. et al. Removal of emerging micropollutants from wastewater by activated carbon adsorption: Experimental study of different activated carbons and factors influencing the adsorption of micropollutants in wastewater. J. Environ. Chem Eng. 4, 1102-1109 (2016).

10. Martín de Vidales, M. J., Millán, M., Sáez, C., Cañizares, P. \& Rodrigo, M. A. Irradiated-assisted electrochemical processes for the removal of persistent pollutants from real wastewater. Sep. Purif. Technol. 175, 428-434 (2017).

11. Neoh, C. H., Noor, Z. Z., Mutamim, N. S. A. \& Lim, C. K. Green technology in wastewater treatment technologies: Integration of membrane bioreactor with various wastewater treatment systems. Chem. Eng. J. 283, 582-594 (2016).

12. Park, H., Park, Y., Kim, W. \& Choi, W. Surface modification of $\mathrm{TiO}_{2}$ photocatalyst for environmental applications. J. Photochem. Photobiol. C-Photochem. Rev. 15, 1-20 (2013).

13. Nakata, K., Ochiai, T., Murakami, T. \& Fujishima, A. Photoenergy conversion with $\mathrm{TiO}_{2}$ photocatalysis: New materials and recent applications. Electrochim. Acta. 84, 103-111 (2012).

14. Reddy, K. R., Hassan, M. \& Gomes, V. G. Hybrid nanostructures based on titanium dioxide for enhanced photocatalysis. Appl. Catal. A-Gen. 489, 1-16 (2015).

15. Zhou, P., Yu, J. \& Jaronie, M. All-Solid-State Z-Scheme Photocatalytic Systems[J]. Adv. Mater. 26, 4920-4935 (2014).

16. Liu, J., He, Z., Khoo, S. Y. \& Tan, T. T. A new strategy for achieving vertically-erected and hierarchical $\mathrm{TiO}_{2}$ nanosheets array/carbon cloth as a binder-free electrode for protein impregnation, direct electrochemistry and mediator-free glucose sensing. Biosens Bioelectron. 77, 942-949 (2016).

17. Ma, L., $\mathrm{Zhu}, \mathrm{Y}$. \& Li, X. The architecture of carbon fiber- $\mathrm{TiO}_{2}$ nanorods hybrid structure in supercritical water for reinforcing interfacial and impact properties of CF/epoxy composites. Polym. Test. 66, 213-220 (2018).

18. Cai, X., Li, J. \& Liu, Y. Titanium dioxide-coated biochar composites as adsorptive and photocatalytic degradation materials for the removal of aqueous organic pollutants. J. Chem. Tech. \& Biotech. 93, 783-791 (2018).

19. Lei, J., Chen, Y. \& Shen, F. Surface modification of $\mathrm{TiO}_{2}$ with $\mathrm{g}-\mathrm{C}_{3} \mathrm{~N}_{4}$ for enhanced UV and visible photocatalytic activity. J. Alloy. Compd. 631, 328-334 (2015).

20. Mohini, R. \& Lakshminarasimhan, N. Coupled semiconductor nanocomposite g- $\mathrm{C}_{3} \mathrm{~N}_{4} / \mathrm{TiO}_{2}$ with enhanced visible light photocatalytic activity. Mater. Res. Bull. 76, 370-375 (2016).

21. Jo, W.-K. \& Natarajan, T. S. Influence of $\mathrm{TiO}_{2}$ morphology on the photocatalytic efficiency of direct Z-scheme g- $\mathrm{C}_{3} \mathrm{~N}_{4} / \mathrm{TiO}_{2}$ photocatalysts for isoniazid degradation. Chem. Eng. J. 281, 549-565 (2015)

22. Rangel-Mendez, J. R., Matos, J., Cházaro-Ruiz, L. F., González-Castillo, A. C. \& Barrios-Yáñez, G. Microwave-assisted synthesis of C-doped $\mathrm{TiO}_{2}$ and $\mathrm{ZnO}$ hybrid nanostructured materials as quantum-dots sensitized solar cells. Appl. Surf. Sci. 434, 744-755 (2018).

23. Teng, F. et al. Preparation of black $\mathrm{TiO}_{2}$ by hydrogen plasma assisted chemical vapor deposition and its photocatalytic activity. Appl. Catal. B-Environ. 148-149, 339-343 (2014).

24. Cheng, X., Liu, H., Chen, Q., Li, J. \& Wang, P. Preparation of graphene film decorated $\mathrm{TiO}_{2}$ nano-tube array photoelectrode and its enhanced visible light photocatalytic mechanism. Carbon. 66, 450-458 (2014).

25. Cai, Q., Hu, Y., Liu, Y. \& Huang, S. Growth of carbon nanotubes from titanium dioxide nanoparticles. Appl. Surf. Sci. 258, 8019-8025 (2012).

26. Huang, J. F. et al. Facile synthesis of porous hybrid materials based on Calix-3 dye and $\mathrm{TiO}_{2}$ for high photocatalytic water splitting performance with excellent stability. J. Mater. Chem. A. 7, 2993-2999 (2019).

27. Guo, W., Zhang, F., Lin, C. \& Wang, Z. L. Direct growth of $\mathrm{TiO}_{2}$ nanosheet arrays on carbon fibers for highly efficient photocatalytic degradation of methyl orange. Adv Mater. 24, 4761-4764 (2012).

28. Long, M., Zheng, L., Tan, B. \& Shu, H. Photocatalytic self-cleaning cotton fabrics with platinum (IV) chloride modified $\mathrm{TiO}_{2}$ and $\mathrm{N}-\mathrm{TiO}_{2}$ coatings. Appl. Surf. Sci. 386, 434-441 (2016).

29. Zhang, X., Jie, Y. \& Nie, Z. Lead-free and amorphous organic-inorganic hybrid materials for photovoltaic applications: mesoscopic $\mathrm{CH}_{3} \mathrm{NH}_{3} \mathrm{MnI}_{3} / \mathrm{TiO}_{2}$ heterojunction. RSC Adv. 7, 37419-37425 (2017).

30. Dassanayake, R. S., Rajakaruna, E. \& Abidi, N. Preparation of aerochitin- $\mathrm{TiO}_{2}$ composite for efficient photocatalytic degradation of methylene blue. J. Appl. Polym. Sci. 135, 45908 (2018).

31. Zhang, X., Chen, W., Lin, Z. \& Shen, J. Photocatalytic Degradation of a Methyl Orange Wastewater Solution Using Titanium Dioxide Loaded on Bacterial. Cellulose. Synth. React. Inorg. Met.-Org. Nano-Metal Chem. 41, 1141-1147 (2011).

32. Wu, S., Bo, D. \& Lu, A. Biocompatible chitin/carbon nanotubes composite hydrogels as neuronal growth substrates. Carbohydr Polym. 174, 830-840 (2017).

33. Vimal Kumar, K., Appa Rao, B. V. \& Hebalkar, N. Y. Phosphorylated chitin as a chemically modified polymer for ecofriendly corrosion inhibition of copper in aqueous chloride environment. Res. Chem. Intermed. 43, 5811-5828 (2017).

34. Liang, S., Dang, Q. \& Liu, C. Characterization and antibacterial mechanism of poly(aminoethyl) modified chitin synthesized via a facile one-step pathway. Carbohydr Polym. 195, 275-287 (2018).

35. Li, C., Sun, Z., Xue, Y., Yao, G. \& Zheng, S. A facile synthesis of $\mathrm{g}_{-} \mathrm{C}_{3} \mathrm{~N}_{4} / \mathrm{TiO}_{2}$ hybrid photocatalysts by sol-gel method and its enhanced photodegradation towards methylene blue under visible light. Adv. Powder Technol. 27, 330-337 (2016).

36. Sridharan, K., Jang, E. \& Park, T. J. Novel visible light active graphitic $\mathrm{C}_{3} \mathrm{~N}_{4}-\mathrm{TiO}_{2}$ composite photocatalyst: Synergistic synthesis, growth and photocatalytic treatment of hazardous pollutants. Appl. Catal. B-Environ. 143, 718-728 (2013)

37. Zhukova, L. V., Kiwi, J. \& Nikandrov, V. V. $\mathrm{TiO}_{2}$ nanoparticles suppress Escherichia coli cell division in the absence of UV irradiation in acidic conditions. Colloids Surf B Biointerfaces. 97, 240-247 (2012).

38. Li, Y., Yang, C. \& Guo, X. Effects of humic acids on the aggregation and sorption of nano-TiO . Chemosphere. 119, 171-176 (2015).

39. Xing, M., Zhang, J. \& Chen, F. New approaches to prepare nitrogen-doped $\mathrm{TiO}_{2}$ photocatalysts and study on their photocatalytic activities in visible light. Appl. Catal. B-Environ. 89, 563-569 (2009).

40. Hung, M.-C., Weng, C.-H. \& Lin, Y.-H. Effectiveness of $\mathrm{ZnO} /$ carbon-based material as a catalyst for photodegradation of acrolein. Carbon. 66, 93-104 (2014).

41. Lin, Y.-T., Weng, C.-H., Lin, Y.-H., Shiesh, C.-C. \& Chen, F.-Y. Effect of C content and calcination temperature on the photocatalytic activity of C-doped $\mathrm{TiO}_{2}$ catalyst. Sep. Purif. Technol. 116, 114-123 (2013).

42. Zhou, J., Bao, L., Wu, S., Yang, W. \& Wang, H. Chitin based heteroatom-doped porous carbon as electrode materials for supercapacitors. Carbohydr Polym. 173, 321-329 (2017).

43. Jia, T., Fu, F., Yu, D., Cao, J. \& Sun, G. Facile synthesis and characterization of $\mathrm{N}$-doped $\mathrm{TiO}_{2} / \mathrm{C}$ nanocomposites with enhanced visible-light photocatalytic performance. Appl. Surf. Sci. 430, 438-447 (2018).

\section{Acknowledgements}

This work was financially supported by the National Natural Science Foundation of China (Grant No. 51872268) and the Fundamental Research Funds for the Central Universities (Grant No. 2652018288).

\section{Author contributions}

K.M. and X.W.W. conceived and designed the experiments. K.M. carried out the experiments. K.M., X.W.W., X.M., Y.G.L., M.H.F. and Z.H.H. analyzed the data and all authors discussed the results. K.M. wrote the paper. 


\section{Competing interests}

The authors declare no competing interests.

\section{Additional information}

Correspondence and requests for materials should be addressed to X.W.

Reprints and permissions information is available at www.nature.com/reprints.

Publisher's note Springer Nature remains neutral with regard to jurisdictional claims in published maps and institutional affiliations.

(c) (i) Open Access This article is licensed under a Creative Commons Attribution 4.0 International License, which permits use, sharing, adaptation, distribution and reproduction in any medium or format, as long as you give appropriate credit to the original author(s) and the source, provide a link to the Creative Commons license, and indicate if changes were made. The images or other third party material in this article are included in the article's Creative Commons license, unless indicated otherwise in a credit line to the material. If material is not included in the article's Creative Commons license and your intended use is not permitted by statutory regulation or exceeds the permitted use, you will need to obtain permission directly from the copyright holder. To view a copy of this license, visit http://creativecommons.org/licenses/by/4.0/.

(c) The Author(s) 2019 